\title{
Proceeding
}

6th ISPAS International Workshop, 22-23 March 2016. International Society of Performance Analysis of Sport. Carlow, Ireland

\section{The use, integration and value of performance analysis to GAA coaches}

\author{
DENISE MARTIN ${ }^{1,3}$, ALAN SWANTON $^{2}$, DENISE MCGRATH ${ }^{3}$, JONATHON BRADLEY4 $^{4}$ \\ ${ }^{1}$ School of Business and Humanities, Institute of Technology, Dublin, Ireland \\ 2Irish Institute of Sport, Dublin, Ireland \\ ${ }^{3}$ School of Public Health, Physiotherapy and Sports Science, University College Dublin, Dublin, Ireland \\ ${ }^{4}$ Sports Institute Northern Ireland, University of Ulster, Northern Ireland
}

\begin{abstract}
Performance analysis (PA) has become integral to the multi-million euro preparation of intercounty GAA teams (GAA, 2013). With little research on the coaching practice of GAA coaches, this paper explores their engagement with PA. Its aims were to examine the use, integration and value of PA to coaches. A sample of 12,500 (minimum level 1 Coaching Ireland qualified) coaches were selected to complete an online-survey with 538 respondents across 37 sports. As the highest responding cohort $(n=144)$, data for the GAA coaches was isolated for further analysis. PA was used by $49 \%$ of GAA coaches. These coaches were more likely to have $10+$ years coaching experience $(X i 2=20.7 p=0)$; be qualified beyond GAA Award $1(X i 2=14.0 p=0)$ and coach at intercounty level $(\mathrm{Xi} 2=12.3 p=0)$. Coaches using PA had access primarily to match statistics (81\%); only $49 \%$ had access to match video. The most popular tools for data collection were hand notation (65\%), Dartfish (38\%) and Apps (38\%). Coaches cited resources and knowledge as key barriers to progressing their use of PA. Reliability of information was not identified as an issue. $88 \%$ of coaches using PA felt it was important / essential to their practice. The findings indicate that GAA coaches have substantially more access to quantitative information compared to video feedback. This lack of video to contextualise and validate data has potential to hamper the interpretation of information by a coach thus impacting their subsequent interventions. In GAA coach education, more emphasis could be placed on the importance of contextualising statistics with video and the potential of video feedback to players. Coaches should be encouraged to question the reliability of match statistics and equipped with appropriate strategies to minimise errors in data collection. Key words: PERFORMANCE ANALYSIS, GAA, COACH, IRELAND.
\end{abstract}

\section{Cite this article as:}

Martin, D., Swanton, A., McGrath, D., \& Bradley, J. (2017). The use, integration and value of performance analysis to GAA coaches. Journal of Human Sport and Exercise, 12(2proc), S492-S501. doi:https://doi.org/10.14198/jhse.2017.12.Proc2.02

Corresponding author. School of Business and Humanities, Institute of Technology, Blanchardstown, Dublin 15, Ireland. 6th ISPAS International Workshop, 22-23 March 2016. International Society of Performance Analysis of Sport. Carlow, Ireland. JOURNAL OF HUMAN SPORT \& EXERCISE ISSN 1988-5202

(c) Faculty of Education. University of Alicante

doi:10.14198/jhse.2017.12.Proc2.02

S492 | 2017| Proc2 | VOLUME 12

C 2017 University of Alicante 


\section{INTRODUCTION}

Collectively Gaelic games are the largest participation sports in Ireland with in excess of half a million members (GAA, 2014). The family of games consisting Gaelic of football, hurling, court handball and road bowls, are played at a variety of levels with senior intercounty competitions considered elite. Hurling and Gaelic football All-Ireland finals annually attract over 165,000 spectators to Gaelic Athletic Association (GAA) head-quarters in Croke Park. The GAA is an amateur organisation and the players do not get paid, however, resources are available for professional sport science and medical support to prepare elite teams (Keyes, 2016). In the last 15 years, performance analysis (PA) has become integral to this multi-million euro preparation of intercounty GAA teams (GAA, 2013). PA can be described as the provision of reliable and valid information on performance to coaches and athletes with the intention to improve future performance (O'Donoghue, 2015).

Academic literature has been slow to catch up with coaching practices, and little research examines the role of PA in the GAA from a tactical or technical perspective (Reilly \& Collins, 2008). In Gaelic football, Bradley and O'Donoghue (2011) investigated the characteristics of counterattacks, while Carroll (2013) focused on the differences in performance variables according to team ranking. Gilmore (2008) examined the prevalence of particular skills in hurling and a skill evaluation of kicking and striking in hurling and football was conducted by Ball and Horgan (2013). Martin and colleagues' (2004) case study provides an insight into how PA was integrated into coaching practice within a senior intercounty football team, describing regular match analysis and video feedback interventions in a VHS era. Byrne and Byrne (2016, in press), illustrate a similar process over ten games with the 2015 All-Ireland Hurling Champions, Kilkenny. These and Mahoney's (2002) case study presentation of his role as a sport psychologist to a senior intercounty football team are the only academic windows into coaching practices at elite level in the GAA. A "lack of openness within the top teams to share best practice" (Ulster-GAA, 2012, p. 34) potentially explains the absence of literature in the field. Looking beyond the academic realms, a growing number of high profile GAA coaching memoirs (Daly \& O'Connor, 2014; Harte \& Shannon, 2003; McGuinness \& Duggan, 2015) reveal how the modern GAA performance analyst is an integral support to the coaching team, managing a systematic programme of match analysis and feedback, using opposition analysis and motivational compilations.

The use, integration and value of PA to coaching practices has been examined by several researchers (Blaze, Atkinson, Harwood, \& Cale, 2004; Butterworth, Turner, \& Johnstone, 2012; Groom \& Cushion, 2004; Mooney et al., 2015; Reeves \& Roberts, 2013; Wright, Atkins, \& Jones, 2012). Most were sport specific in soccer, rugby, hockey, badminton and swimming, and were interview based. Wright et al., (2012) and Mooney et al., (2015) surveyed 46 and 268 elite coaches respectively, reporting regular use of video feedback. Due to the myriad of factors which influence performance, measuring the impact of PA has proven extremely difficult (O'Donoghue \& Mayes, 2013). Thus survey data on coaches' perceptions of the value of PA is a potentially useful surrogate measure of the role of PA in coaching practice. There has been no exploration of the perceptions of a wider range of coaches to PA or of the factors differentiating PA users and non-users. With little research on the coaching practice of GAA coaches, this paper explores their engagement with PA. Its aims were to examine which GAA coaches were using PA; what elements they were using and how these were integrated into practice; how PA was valued and barriers to its use.

\section{MATERIAL AND METHODS}

A sample of 12,500 coaches from the Coaching Ireland database was selected to complete an online-survey relating to their engagement with various aspects of PA. Coaches ranged from volunteer to elite coaches. To 
be included in the sample, coaches had to hold at least a level 1 coaching qualification, allowing the investigation to gain a broad understanding of perceptions of PA in Ireland. 538 coaches responded completing the online survey across 37 sports. As the highest responding cohort $(n=144)$, data for the GAA coaches was isolated for further analysis. Of the $144 \mathrm{GAA}$ coaches, $89 \%$ were male and the median age was 40-49 years old (40\%). The original categories of 'level of athlete coached' were adapted appropriately for GAA to senior intercounty, intercounty age-grade and club / university / school.

Categories of questioning included (i) coaching profile, experience, qualifications, roles, (ii) elements and tools of PA used and its integration into the coaching process, (iii) perceived value of PA to coaches, (iv) barriers to the use of PA. The majority of questions were closed and pre-coded, similar to the validated tool used by Wright et al., (2012). Some questions were answered by only coaches using PA allowing the investigation to target explicit users. All of the coaches involved with the study were contacted via email and requested to complete the anonymised questionnaire in Survey Monkey.

The majority of the data presented in the study are descriptive in nature. Statistical analyses were carried out using SPSS (version 20.0, IBM Corp.). The Chi-Square test was used to test for association between a range of variables such as coaching qualifications and the proportion of coaches using PA. A significance level of 0.05 was used for all analyses.

\section{RESULTS}

\section{Coach Profiles}

Table 1. Percentage of PA users within each profile factor. P value relates to Chi Squared test of association PA use and profile differences.

\begin{tabular}{|c|c|c|c|}
\hline Profile Factor & Coach Profile & $\%$ PA Users & P Value \\
\hline \multirow{2}{*}{ Coaching Experience } & $<10$ Years & 33 & \\
\hline & $10+$ Years & 66 & 0.00 \\
\hline \multirow[t]{2}{*}{ Coaching Qualification } & Level 1 Qualified & 37 & \\
\hline & Level 2+ NGB Qualified & 70 & 0.00 \\
\hline \multirow{2}{*}{ Level of Athlete Coached } & University / Club / School & 32 & \\
\hline & Intercounty Senior / Age Grade & 76 & 0.00 \\
\hline \multirow[t]{2}{*}{ Remuneration Status } & Volunteer (With / without expenses) & 45 & \\
\hline & Paid Coaching Position - FT or PT & 81 & $<0.006$ \\
\hline
\end{tabular}

Just under half $(49 \%)$ of GAA coaches surveyed used PA. There is evidence of a statistically significant association between the use of PA and increased coaching experience, level of coaching qualification, level of athlete coached (intercounty) and whether the coach was in a paid coaching position (Table 1). Respondents varied in coaching experience; $25 \%$ had less than 5 years, 37\% had $6-10$ years, $15 \% 11-15$ years and $23 \%$ with $15+$ years' experience. The majority of coaches $(65 \%)$ were qualified at GAA Award 1 level, with $35 \%$ qualified to Award 2 or beyond. A lot of coaches worked with multiple teams. When the coaches were categorised according to the highest level coached, $13 \%$ were senior intercounty coaches, $15 \%$ coached at intercounty age grade and $62 \%$ coached at university / club or school level. $78 \%$ of coaches were unpaid volunteers, $11 \%$ were volunteers receiving expenses, $3 \%$ held part time coaching roles, while $8 \%$ had full time roles. 


\section{Use and Integration of PA}

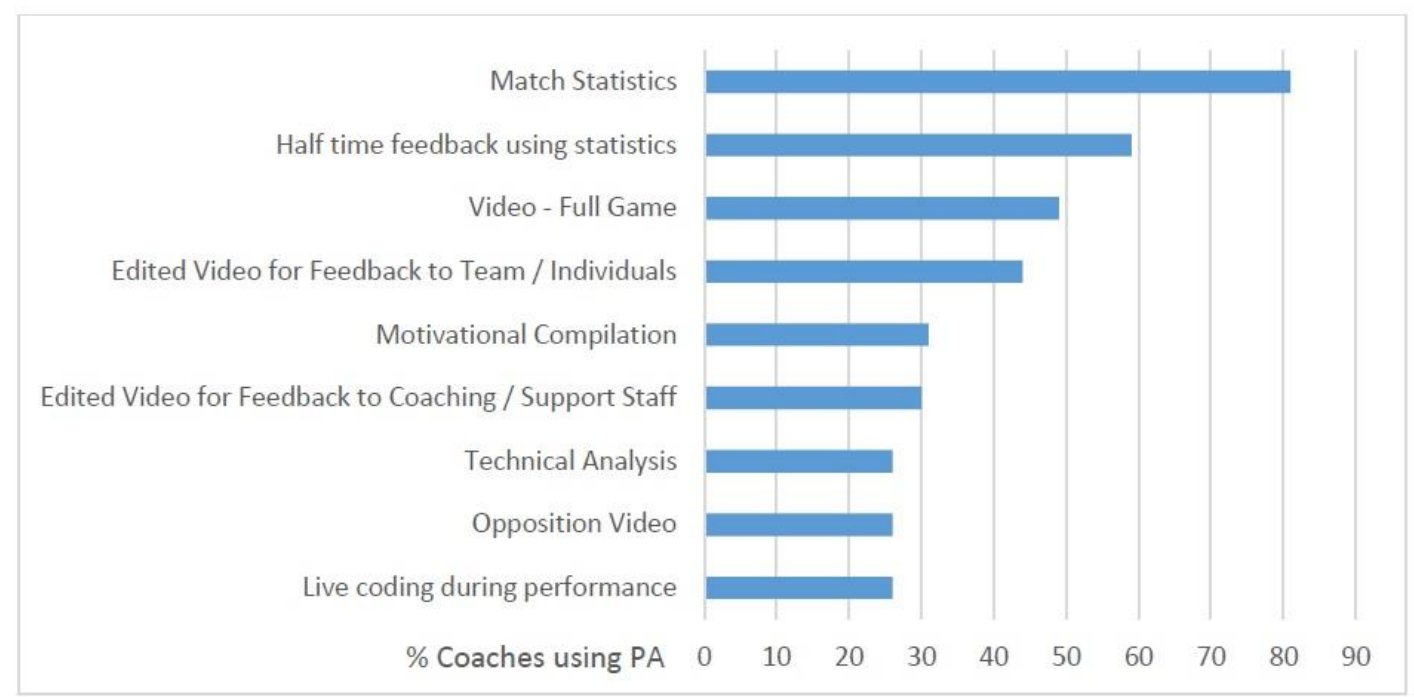

Figure 1. Elements of PA which GAA coaches have most access to. $N=70$

Table 2. Range of PA tools used by coaches. $N=70$

\begin{tabular}{llr}
\hline Tools & & \% Coaches \\
\hline Hand notation & Dartfish & 65 \\
Computerised Analysis Software: & Focus X2 & 35 \\
& SportsCode & 7 \\
& Kinovea & 6 \\
Apps for Phone / Tablets & & 3 \\
Video editing software e.g. Moviemaker & & 32 \\
Performa Sports & & 17 \\
\hline
\end{tabular}

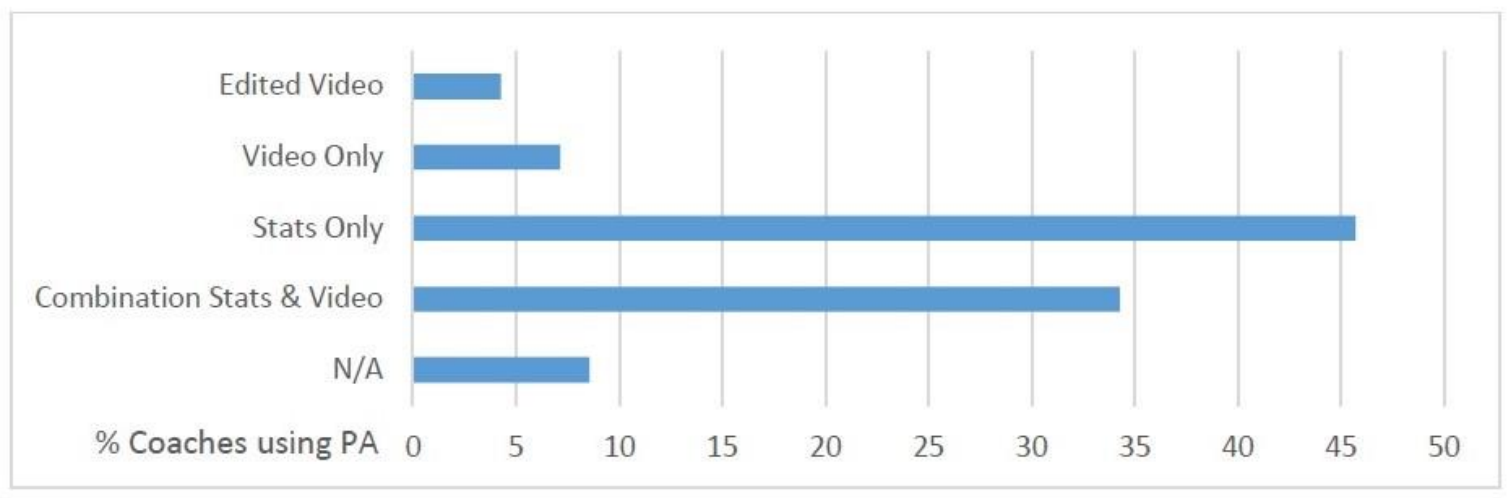

Figure 2. The type of feedback provided to coaches using PA. $N=70$ 


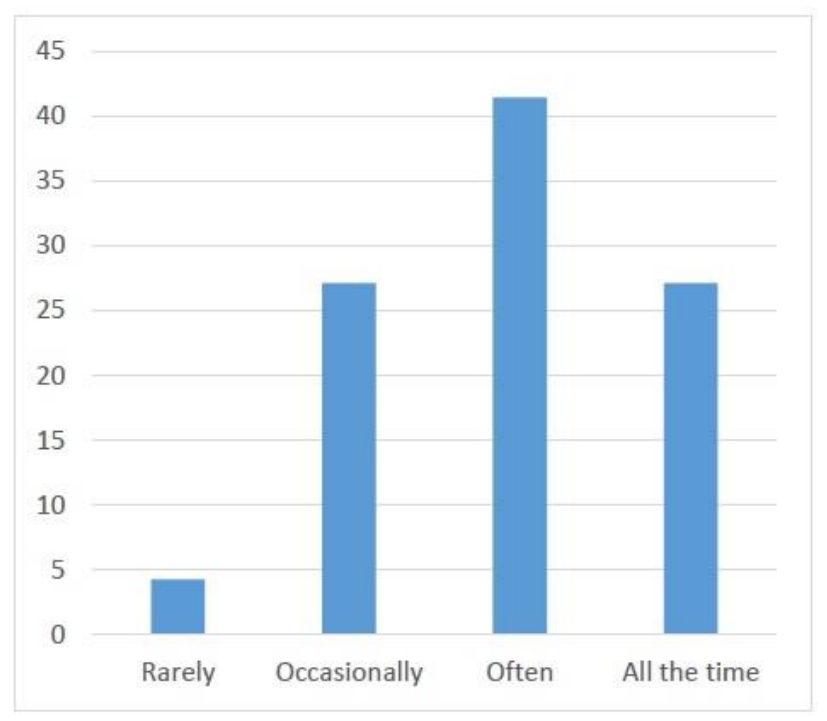

Figure 3. Frequency that PA informs the content of training sessions for coaches using PA. $N$ $=70$. (Rarely, 2-3 times per season; Occasionally, 4-6 times per year; Often, 4-5 times per month).

GAA coaches (35\%) reported a similar level of access to the support of a performance analyst as their peers in rugby $(41 \%)$, hockey $(33 \%)$ and soccer $(30 \%)$. When asked what elements of PA they used (Figure 1), match statistics was the most prominent $(81 \%)$, with only $49 \%$ having access to match video. In response to a supplementary question, the majority of coaches indicated they are never $(39 \%)$ or rarely (20\%) provided with post-match video. $20 \%$ of coaches reported post-match video available often or all the time. An investigation into the range of PA tools coaches were using (Table 2), reveals hand notation to be the most prominent (65\%). Accounting for coaches using multiple software brands, the combined usage of computerised analysis software was $40 \%$ and Dartfish was the most popular (35\%). A third of coaches (34\%) are receiving combinations of video and statistical feedback (Figure 2), however it is more common for coaches to receive statistical feedback only (46\%). When asked about the frequency that PA informed the content of their training sessions, $69 \%$ of coaches felt this was often or all the time (Figure 3 ).

\section{Value of and Demand for PA}

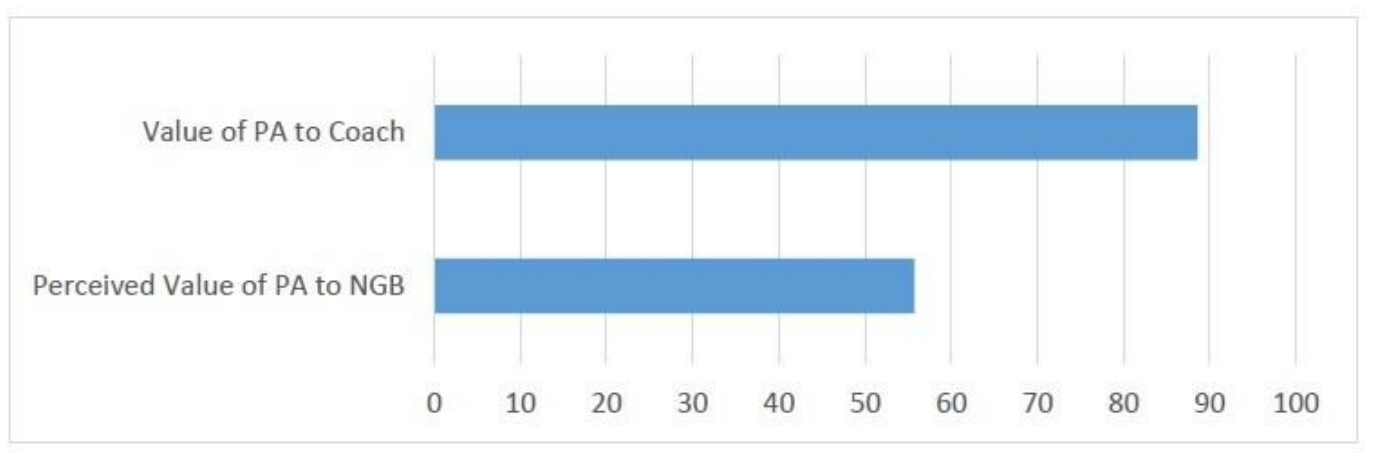

Figure 4. The percentage of coaches rating PA as important to essential, to them and their NGB. $N=70$ coaches. 
When the coaches using PA were asked if they would like to use more PA within their coaching, 94\% said yes. The majority of coaches were positive about the value of PA (Figure 4), indicating that it was important $(19 \%)$, very important $(49 \%)$ or essential $(21 \%)$ to their practice. Based on the perceived commitment of money and resources, coaches were not convinced that their organisation valued PA as highly.

\section{Barriers to Use of PA}

A variety of factors were reported as barriers to coaches' use of PA (Table 3 ). Knowledge $(27 \%)$ was the most prominent issue for coaches not using PA, significantly less so for those using PA. There is evidence of a statistically significant association between using PA and the identification of cost, availability of equipment and time taken to complete analysis as the main barriers to use of PA. None of the coaches reported concerns about reliability as a barrier to progress. When asked if they would like training on how to integrate PA effectively into their practice, $87 \%$ indicated they would.

\section{DISCUSSION}

The purpose of this research was to explore the engagement of GAA coaches with PA, examining its use, integration and perceived value to the coaching process, and the factors precluding the use of PA. The findings revealed that almost half $(49 \%)$ of coaches surveyed using PA in their practice and provides insights into the profile differences between users and non-users. Coach responses build a picture of the PA tools used and how they inform practice and highlight the challenges for coaches in progressing their use of PA. This, the first survey of coaching practices in the GAA, establishes a benchmark for future assessment of coach use of PA in the GAA. Given that the GAA Games Development team is due to begin a process of mapping coach education outcomes in the new Coach ${ }^{10}$ framework (Horgan \& Daly, 2015), the findings may also have practical value in informing elements relating to observation, quantitative and qualitative analysis and feedback. 
Table 3. Barriers to expanding and progressing the use of PA. $N=144$.

\begin{tabular}{|c|c|c|c|}
\hline Theme & Barrier & $\begin{array}{c}\text { \% Coaches } \\
\text { using no } \\
\text { PA }\end{array}$ & $\begin{array}{c}\% \\
\text { Coaches } \\
\text { using PA }\end{array}$ \\
\hline Knowledge & I would like to know more in order to progress* & 27 & 10 \\
\hline \multirow{3}{*}{ Cost } & Cost of software* & 22 & 72 \\
\hline & Cost of hardware* & 16 & 50 \\
\hline & Cost of personnel* & 15 & 41 \\
\hline \multirow[t]{3}{*}{ Time } & Time taken to complete analysis (tasks too long / arduous)* & 7 & 35 \\
\hline & Lack of time available to interpret and analyse information & 15 & 27 \\
\hline & $\begin{array}{l}\text { Time lost from training / practice to feed back the } \\
\text { information }\end{array}$ & 8 & 11 \\
\hline \multirow[t]{3}{*}{ Personnel } & Can't find someone to do it & 7 & 17 \\
\hline & Players' responsiveness to video has been overly negative & 1 & 4 \\
\hline & $\begin{array}{l}\text { Other members of the support teams responsiveness to } \\
\text { feedback }\end{array}$ & 5 & 6 \\
\hline \multirow{2}{*}{$\begin{array}{l}\text { Other } \\
\text { resources }\end{array}$} & Availability of equipment i.e. laptop, PC's, screen* & 11 & 30 \\
\hline & $\begin{array}{l}\text { Availability of appropriate room / space to hold feedback } \\
\text { sessions }\end{array}$ & 1 & 5 \\
\hline Value / Nature & Usability of the information provided & 3 & 9 \\
\hline \multirow{4}{*}{ of Information } & Reliability of the information provided & 0 & 0 \\
\hline & Concern over information overload & 8 & 15 \\
\hline & Concern over analysis as a distraction & 7 & 6 \\
\hline & Don't consider that the analysis adds value & 3 & 0 \\
\hline $\mathrm{N} / \mathrm{A}$ & Not applicable & 43 & 5 \\
\hline
\end{tabular}

\section{Coach Profiles}

This study has identified several factors which have a significant association with the use of PA in coaching practice. The key indicators were Award 2 qualification, 10+ years' coaching experience, coaching at intercounty level and remuneration status. This is possibly reflective of a juncture in a coach's career where they have gained sufficient experience to have access to more talented athletes and increased resources. The identification of Award 2 as a threshold to use of PA is important to coach education designers as it provides an opportunity to target material and support to the development of PA expertise at appropriate stages in their career.

\section{Use and Integration of PA}

Statistics, provided post-match and at half time, are the most dominant form of PA evident in this survey of Gaelic games, perhaps due to the pervasive role they play in GAA media coverage. BBC Northern Ireland introduced half and full time match statistics to their Gaelic football analysis in 2003 and since then statistics have become integral to broadcast and print media coverage of Gaelic football and hurling games (Whelan, 2013). Another potential factor in this is the cost associated with taking and using video. Nearly half (46\%) of coaches using PA received statistical feedback only and it is likely this data was collected using hand notation, given its prominence as the most used PA tool (65\%). Hughes (2008), while a strong advocate for the use of notational analysis, warns that its accuracy and value depends on quality of the input. James and colleagues (2007) identified the process of re-checking data with video as the gold standard in reliability procedure. The fact that so many coaches reported receiving statistics only with no access to video to verify 
the data raises some questions over the reliability of these statistics. It may be useful for GAA coach educators to emphasise the importance of critically appraising the reliability of data and to ensure coaches are well equipped with strategies to ensure hand notation is as reliable and accurate as possible (Carling, Williams, \& Reilly, 2005).

Video is not only important for reliability, it also allows coaches and athletes to figure out 'why' and 'how' performance occurred through qualitative analysis (P. O'Donoghue, 2015) and video is often integral to feeding information back to athletes (Maslovat \& Franks, 2015). A large proportion of PA users (59\%) rarely or never had access to video, thus their ability to effectively diagnose and respond to issues presenting in the statistical data, is diminished. Those coaches with access to video used it in a variety of ways, feeding back to their teams and support staff, doing technical analysis, conducting opposition analysis and using motivational compilations. The range of PA elements employed suggests evidence of some systematic use of PA, similar to the professional PA support described by Wright et al., (2014) in soccer. Changes in performance are generally affected through strategies implemented in practice sessions (Hughes, 2008) and $69 \%$ of coaches reported that PA informs the content of their training at least $4-5$ times a month, indicating some methodical use of PA. This evidence of regular use of video feedback and the role of PA systematically informing training in some coaches, concurs with the intervention schedule of a senior intercounty team outlined in Martin et al., (2004) and Byrne and Byrne (2016, in press). These papers reported the role of the performance analyst within an intercounty football and hurling team respectively, this study found over one third $(35 \%)$ of GAA coaches using PA reported having access to an analyst. These coaches were significantly more likely to have increased access to video and use computerised analysis software. Cost may be the main barrier to accessing computerised analysis software which is used by just $40 \%$ of PA users, however the prominence of phone or tablet based 'apps' (32\%) could indicate a shift towards mobile technology. Performa Sports was the only mobile cloud based analysis platform identified, used by $6 \%$ of coaches.

\section{Value of and Demand for PA}

The vast majority of coaches using PA (89\%) valued it as important - essential to their practice, consistent with the positive ratings and assessments of PA by coaches in similar investigations in other sports (Blaze et al., 2004; Butterworth et al., 2012; Groom \& Cushion, 2004; Wright et al., 2012). Coaches using PA indicated overwhelmingly ( $94 \%$ ) that they would like to use more. These findings assist in building the body of evidence supporting the role of PA as a key tool in their practice. Given the difficulty in proving performance impact attributable solely to PA (O'Donoghue, 2010), perceptions of value placed on PA may prove a useful surrogate measure. There was a considerable difference in how coaches perceived their NGB valued PA, $56 \%$ important - essential. This is perhaps reflective of differing attitudes to PA. While coaches have been fast to embrace the potential of PA (Harte \& Shannon, 2003), a case in 2015 highlights that administrators may be less so. The decision by Munster Council to ban live video feeds (Cummiskey, 2015) for intercounty matches was seen by many as a backward step given that this study shows $26 \%$ of PA users availing of live coding information.

\section{Barriers to Use of PA}

Consistent with the findings of similar surveys, time (Mooney et al., 2015); cost of software, hardware and personnel and availability of equipment (Wright et al., 2012) were the key barriers identified by coaches to expanding their use of PA. A novel aspect of this study is the comparison between coaches using and not using PA. Knowledge was highlighted as an obstacle to progress by a quarter of coaches (27\%) not using PA, but it was significantly less of a barrier to PA users (10\%). Relating this to the differences in profile between the two groups, it would appear that attaining GAA Award 2 qualification coupled with the experiential learning acquired by more years coaching may be addressing the knowledge deficit between PA 
users and non-users. Both PA users (93\%) and non-users (81\%) indicated they would like training on how to integrate PA effectively into their practice suggesting strong interest in professional development training in this area.

\section{CONCLUSIONS AND COACHING IMPLICATIONS}

We are aware of the widely cited limitations of survey methodologies that could have potentially affected our data, such as responder bias, reduced validity of closed-ended questions and subjective interpretation of rankings. However, the findings from this study provide a first insight into the application of PA in GAA coaching practices. Despite their amateur status, this paper found a small proportion of GAA coaches engaging with PA with a level of sophistication that appears similar to professional sports. Further research examining the coaching practice of intercounty coaches, investigating the frequency of feedback and structure of interventions for amateur players would be welcome, particularly case studies. The overall PA usage figure of $49 \%$ in Gaelic games will act as a benchmark for future studies. The findings suggest demand for continued and expanded use of PA, which is highly valued by coaches in their practice.

The study has identified GAA Award 2 as a key threshold between using and not using PA, potentially allowing coach education designers target material and support to the development of PA expertise at appropriate stages in their career. Findings suggest that in GAA coach education, more emphasis could be placed on the importance of contextualising statistics with video and the potential of video feedback to players. Coaches should be encouraged to question the reliability of match statistics and be equipped with appropriate strategies to minimise errors in data collection. Given the trend towards using a performance analyst, it may be beneficial to provide support to coaches on defining roles, building relationships, developing appropriate analysis systems, interpreting information and directing feedback.

\section{REFERENCES}

1. Ball, K., \& Horgan, B. (2013). Performance analysis of kicking and striking skills in Gaelic sports. Performance Analysis of Sport IX, 117.

2. Blaze, A., Atkinson, G., Harwood, C., \& Cale, A. (2004). Prevalence and perceptions of performance analysis in the English Premier Association Football League. Performance Analysis of Sport V, Centre for Performance Analysis, University of Wales Institute, Cardiff, 79-83.

3. Bradley, J., \& O'Donoghue, P. G. (2011). Counterattacks in elite Gaelic football competition. Int J PA Sport, 11(1), 159-170.

4. Butterworth, A. D., Turner, D. J., \& Johnstone, J. A. (2012). Coaches' perceptions of the potential use of performance analysis in badminton. Int J PA Sport, 12(2), 452-467.

5. Byrne, L., \& Byrne, E. (2016, in press). A statistical analysis of Kilkenny Senior Hurlers during the 2015 season.

6. Carling, C., Williams, A. M., \& Reilly, T. (2005). Handbook of Soccer Match Analysis. London: Routledge.

7. Carroll, R. (2013). Team Performance Indicators in Gaelic Football and Opposition Effects. Int J PA Sport, 13(3), 703-715.

8. Cummiskey, G. (2015). Munster Council bans live video analysis at grounds. Irish Times.

9. Daly, A., \& O'Connor, C. (2014). Dalo: The Autobiography: Transworld Publishers Limited.

10. GAA. (2013). Gaelic Athletic Association Annual Report to Congress 2013. Dublin: Gaelic Athletic Association. 
11. GAA. (2014). GAA Games Development Report for Irish Sports Council. Dublin: Gaelic Athletic Association.

12. Gilmore, H. J. (2008). The craft of the Caman; A notational analysis of the frequency occurrence of skills used in Hurling. Int J PA Sport, 8(1), 68-75.

13. Groom, R., \& Cushion, C. (2004). Coaches perceptions of the use of video analysis: A case study. Insight, 7(3), 56-58.

14. Harte, M., \& Shannon, K. (2003). Kicking Down Heaven's Door: All-Star Print Ltd.

15. Horgan, P., \& Daly, P. (2015). The Role of the Coach Developer in Supporting and Guiding Coach Learning A Commentary. Int Sp Coaching J, 2(3), 354-356.

16. Hughes, M. (2008). Notational Analysis for Coaches. In R. L. Jones, M. Hughes, \& K. Kingston (Eds.), An Introduction to Sports Coaching (pp. 101-113). London: Routledge.

17. James, N., Taylor, J., \& Stanley, S. (2007). Reliability procedures for categorical data in Performance Analysis. Int J PA Sport, 7(1), 1-11.

18. Keyes, C. (2016, 5 March, 2016). Cost of running county teams at record levels. Irish Independent.

19. Mahoney, C. (2002). The Multidisciplinary Delivery of Sport Science in Gaelic Football. Science and Football IV, 387-391.

20. Martin, D., Cassidy, D., \& O'Donoghue, P. (2004). The effectiveness of performance analysis in elite Gaelic football. Presented at the World Congress of PA of Sport, GAA Workshop.

21. Maslovat, D., \& Franks, I. M. (2015). The importance of feedback to performance. In M. Hughes \& I. M. Franks (Eds.), Essentials of Performance Analysis in Sport (2 ed., pp. 11-17). London: Routledge.

22. McGuinness, J., \& Duggan, K. (2015). Until Victory Always: A Memoir: Gill \& Macmillan Limited.

23. Mooney, R., Corley, G., Godfrey, A., Osborough, C., Newell, J., Quinlan, L. R., \& G, O. L. (2015). Analysis of swimming performance: perceptions and practices of US-based swimming coaches. $J$ Sports Sci, 1-9. doi: 10.1080/02640414.2015.1085074

24. O'Donoghue, P. (2015). An introduction to performance analysis of sport. London: Routledge.

25. O'Donoghue, P. G. (2010). Research methods for sports performance analysis. London;: Routledge.

26. O'Donoghue, P. G., \& Mayes, A. (2013). Performance analysis, feedback and communication in coaching. In T. McGarry, P. G. O'Donoghue, \& J. Sampaio (Eds.), Routledge Handbook of Sports Performance Analysis. (pp. 155-164). London: Routledge.

27. Reeves, M. J., \& Roberts, S. J. (2013). Perceptions of Performance Analysis in Elite Youth Football. Int J PA Sport, 13(1), 200-211.

28. Reilly, T., \& Collins, K. (2008). Science and the Gaelic sports: Gaelic football and hurling. Eur J Sport Sci, 8(5), 231-240.

29. Ulster GAA. (2012). Ulster GAA High-Performance and Talent-Identification and Development Plan 2012-2016. Armagh: Ulster Council GAA.

30. Whelan, D. (2013). The Managers: The tactics and thinkers that transformed Gaelic football. Dublin: Hachette Books Ireland.

31. Wright, C., Atkins, S., \& Jones, B. (2012). An analysis of elite coaches' engagement with performance analysis services (match, notational analysis and technique analysis). Int J PA Sport, 12(2), 436451.

32. Wright, C., Carling, C., \& Collins, D. (2014). The wider context of performance analysis and it application in the football coaching process. Int J PA Sport, 14(3), 709-733. 